\title{
Differences between Staphylococcus aureus lineages isolated from ovine and caprine mastitis but not between isolates from clinical or subclinical mastitis
}

\author{
J. Hoekstra, ${ }^{1,2 *}$ V. P. M. G. Rutten, ${ }^{1,3}$ M. van den Hout, ${ }^{1}$ M. P. Spaninks, ${ }^{2}$ L. Benedictus, ${ }^{1,4}$ and G. Koop ${ }^{2}$ \\ ${ }^{1}$ Department of Infectious Diseases and Immunology, Faculty of Veterinary Medicine, Utrecht University, Yalelaan 1, 3584 CL Utrecht, \\ the Netherlands \\ ${ }^{2}$ Department of Farm Animal Health, Faculty of Veterinary Medicine, Utrecht University, Yalelaan 7, 3584 CL Utrecht, the Netherlands \\ ${ }^{3}$ Department of Veterinary Tropical Diseases, Faculty of Veterinary Science, University of Pretoria, Private Bag X04, Onderstepoort 0110 , \\ South Africa \\ ${ }^{4}$ Division of Infection and Immunity, The Roslin Institute, The University of Edinburgh, Easter Bush, Midlothian EH25 9RG, Scotland
}

\section{ABSTRACT}

Staphylococcus aureus is an important mastitis pathogen, causing both clinical mastitis (CM) and subclinical mastitis (SCM) in small ruminants. In general, CM has a low incidence in sheep and goats but can be very severe and costly. In contrast, subclinical mastitis (SCM) is common but is associated with less cost. For both sheep and goats, $S$. aureus is the main cause of $\mathrm{CM}$ and is associated with SCM cases with a high SCC. Recently, specific lineages of $S$. aureus have been identified that are associated with CM rather than SCM in dairy cows. It is unknown whether specific $S$. aureus lineages are associated with CM in goats and sheep. The aim of this study was to compare the clonal complex (CC), staphylococcal protein A (spa) type, leukocidin lukM$l u k F^{\prime}$ presence, and potential to produce LukMF' in vitro between CM and SCM S. aureus mastitis isolates obtained from sheep and goats. Differences between isolates from different host species were also compared. Ovine (CM, $\mathrm{n}=12 ; \mathrm{SCM}, \mathrm{n}=29$ ) and caprine (CM, n $=14 ; \mathrm{SCM}, \mathrm{n}=30$ ) isolates were obtained from 8 sheep flocks and 8 goat herds in the Netherlands. Overall, the isolates belonged to CC133 (85\%), CC398 (7\%), CC425 (5\%), and CC45 (2\%). Seventeen spa types were found, including 6 novel types; the predominant types were t2678 (34\%), t544 (18\%), and t3583 (18\%). Although CC133 was dominant among both sheep and goat isolates, spa type CC133/t2678 was associated with ovine isolates, whereas CC133/t544 and CC133/t3583 were found mostly in goats. The presence of lukM-lukF' among the $S$. aureus isolates was high (87\%), especially in CC133 (96\%) and CC425 (100\%), but the genes were absent in CC45 and CC398. In vitro-cultured lukM-

Received December 21, 2018

Accepted February 14, 2019.

*Corresponding author: j.hoekstra1@uu.nl
lukF'-positive isolates produced LukM (71 out of 74 positive isolates tested) in the range of 0.4 to $5.0 \mu \mathrm{g} /$ $\mathrm{mL}$. Interestingly, the goat-associated lineages CC133/ t544 and CC133/t3583 produced more LukM in vitro than the sheep-associated CC133/t2678. We found no difference in LukMF' production potential between CM and SCM isolates. In sheep as well as in goats, no association was found between genotype and CM or SCM, demonstrating that the same lineages of $S$. aureus are responsible for both CM and SCM. These results suggest that subclinically infected animals in a herd or flock likely act as the reservoir of $S$. aureus causing CM. This highlights the importance of early identification and control of SCM and suggests that controlling SCM within a herd is an effective intervention to prevent $\mathrm{CM}$ in small ruminants.

Key words: Staphylococcus aureus, mastitis, LukMF', sheep, dairy goat

\section{INTRODUCTION}

Mastitis is a common disease among dairy goats and sheep that is responsible for economic losses due to reduced milk production (Gonzalo et al., 2002; Koop, 2012), decreased milk quality (Barrón-Bravo et al., 2013; Martí De Olives et al., 2013), increased lamb mortality (Arsenault et al., 2008), costs of treatment, and culling (Conington et al., 2008; Koop, 2012). Furthermore, behavioral differences are observed in animals suffering from mastitis; this, together with clinical symptoms, indicates a reduction in animal welfare (Gougoulis and Kyriazakis, 2010). Clinical mastitis (CM) is characterized by the classical signs of inflammation (pain, swelling, heat, erythema, and loss of function), causing visible abnormalities in milk or the udder (Smith and Sherman, 2009). In the present study, subclinical mastitis (SCM) is defined by a positive bacteriological culture from normal-looking milk in the absence 
of clinical symptoms (Koop et al., 2010). Because the use of elevated SCC as an indicator for SCM in small ruminants is debated (de los Campos et al., 2006; Koop et al., 2010), we chose not to consider it to define SCM. Although SCM is common in goats and sheep (Moroni et al., 2005; Vasileiou et al., 2018), it only results in a limited decrease in milk yield (Gonzalo et al., 2002; Koop et al., 2010; Martí De Olives et al., 2013) and relatively low costs for the farmer (Koop, 2012). Many SCM cases are caused by CNS but also by Staphylococcus aureus (Fthenakis, 1994; Moroni et al., 2005). In contrast, CM has a low incidence but is responsible for more economic losses than SCM (e.g., higher reduction in milk yield and quality, increased lamb mortality and the culling of animals), highlighting the importance of CM control to reduce the costs of mastitis on farms (Bergonier et al., 2003; Arsenault et al., 2008; Koop, 2012; Martí De Olives et al., 2013). Most CM cases in sheep and goats are caused by $S$. aureus (Bergonier et al., 2003), and the dominant lineages of $S$. aureus isolated from these animals are clonal complex (CC) 133, CC130, and CC522 (Smith et al., 2014; Merz et al., 2016). Although several studies consider S. aureus isolates from goats and sheep to be part of the same population based on CC, typing techniques with higher resolution, such as staphylococcal protein A (spa) typing, do detect different $S$. aureus lineages associated with the 2 species (Porrero et al., 2012; Eriksson et al., 2013; Azara et al., 2017). Among CC133 isolates obtained from small ruminants, certain spa types were predominantly found in goats (t1166, t7304), and other types (t2678, t9088) were found in sheep (Porrero et al., 2012; Eriksson et al., 2013).

The severity of infectious diseases is determined by the pathogen, the host, and their interaction, but it is largely unclear to what extent the clinical severity of mastitis is driven by host or pathogen factors (Fournier et al., 2008; Rainard et al., 2018a). Recently, we identified a bovine-associated lineage of $S$. aureus (sequencetype 479) that was associated with CM rather than SCM in cattle (Hoekstra et al., 2018). High production of leukocidin LukMF', a ruminant-associated virulence factor that is a potent killer of ruminant neutrophils in vitro (Vrieling et al., 2016), by ST479 S. aureus was the likely explanation for this association with CM. To our knowledge, associations between $S$. aureus lineages and $\mathrm{CM}$ or SCM have not previously been investigated in sheep and goats.

The aim of this study was to describe the genetic diversity of $S$. aureus isolates obtained from cases of ovine and caprine mastitis in the Netherlands and to determine to what extent this variation is associated with $\mathrm{CM}$ or SCM and with host species. Multilocus sequence typing (MLST) and spa genotyping were performed, and the proportion of isolates carrying $l u k M-l u k F^{\prime}$ and their LukMF' production potential were determined.

\section{MATERIALS AND METHODS}

\section{Sample Collection}

A convenience sample of 18 Dutch dairy goat farmers was asked to aseptically collect milk samples from any goat suffering from CM. For the present study, the definition of CM was visible abnormalities in the udder or milk or both. For every case of CM, farmers were asked to fill out a form to record goat ID, date of CM, date of kidding, parity, affected udder half, type of mastitis (gangrenous mastitis or nongangrenous mastitis), clinical symptoms, appearance of the milk, and treatment. The milk samples from $\mathrm{CM}$ were frozen at $-20^{\circ} \mathrm{C}$ by the farmer. At the end of the sampling period, the samples were shipped to the Veterinary Microbiological Diagnostic Center at Utrecht University for bacteriological culture and speciated according to National Mastitis Council guidelines (Hogan, 1999), resulting in $14 S$. aureus CM isolates from 8 herds. The SCM isolates (n $=30$ ), originating from 5 herds that also contributed caprine CM isolates, were used from a previous study on SCM in dairy goats (Koop et al., 2010).

Ovine mastitis isolates were obtained from milk samples from 238 meat sheep from 15 herds. During sampling, udder halves showing abnormalities in appearance of the milk or the udder or both were classified as having CM. All milk samples were cultured on blood agar plates according to National Mastitis Council guidelines (Hogan, 1999), and bacterial species were determined using MALDI-TOF (Jang and Kim, 2018). A positive bacterial culture result in the absence of reported abnormalities in milk or the udder was classified as SCM. A total of 41 S. aureus isolates were found, originating from 8 herds, including 12 samples originating from cases classified as CM and 29 classified as SCM.

\section{Genotyping of Isolates}

Extraction of DNA from $S$. aureus isolates was performed using a boiling protocol as described by Hoekstra et al. (2018). The polymorphic X-region of the spa genes of the isolates was amplified according to the Ridom StaphType standard protocol (www .ridom.org). When standard spa-typing primers failed to yield a PCR product in an isolate, an alternative set of spa primers (Hallin et al., 2009) was used. Amplicons were purified using ExoSAP-IT PCR Cleanup Reagent (Affymetrix, Santa Clara, CA) following the manufacturer's instructions and sequenced using Sanger se- 
quencing (Baseclear, Leiden, the Netherlands). Based on sequenced PCR amplicons, spa types were assigned using BioNumerics version 7.5 (Applied Maths, SintMartens-Latem, Belgium) and the spa-typing plugin. A minimum spanning tree of spa types was created in BioNumerics version 7.5 by the spa clustering methods of the spa-typing plugin using the same settings as described by Mekonnen et al. (2018).

For MLST, a subset of ovine isolates $(\mathrm{n}=10)$ was selected, representing the diversity of spa types among ovine isolates. Typing was performed according to the protocol described on the MLST website (http:/ /saureus.mlst.net). The MLST of caprine isolates was obtained from whole-genome sequence (WGS) data. For WGS, DNA was extracted using a MasterPure gram-positive DNA purification kit (Cambio, Cambridge, UK), and HiSeq sequencing was performed according to the manufacturer's protocol (Illumina Inc., San Diego, CA); genotyping was done based on the assembled genomes of these isolates.

\section{Detection of lukM-IukF' and In Vitro LukM Production}

The PCR amplification of femA, lukM, and lukF' and measurement of in vitro LukMF' production potential was performed as previously described by Hoekstra et al. (2018). Briefly, to measure the LukMF' production potential, isolates were grown in broth under controlled conditions for $8 \mathrm{~h}$ and the LukM concentration in broth was measured using ELISA (Vrieling et al., 2016; Hoekstra et al., 2018).

Presence of lukM-lukF" in WGS of $S$. aureus isolates was investigated by BLASTN using reference sequences for lukM (GenBank accession no. 1262967) and lukF' (GenBank accession no. 1262954). Identity scores higher than $95 \%$ were considered positive for lukM or $l u k F$ '.

\section{Statistical Analysis}

For the LukM ELISA, LukM values were extrapolated from a LukM standard curve using GraphPad Prism 7 software (GraphPad Software, La Jolla, CA). Differences in LukMF' production potential between different lineages were tested by Kruskal-Wallis test followed by Dunn's test in GraphPad Prism 7. To compensate for a possible farm effect on LukMF' production potential, a subset of the LukMF' production potential data set with only a single spa-type value per farm was also used. In case of multiple isolates with the same spa type on a farm, the averaged LukM production of isolates belonging to this spa type was used.

The Mann-Whitney test was used to compare differences in LukMF' production potential between $S$. aureus isolated from sheep and goats and from CM and SCM (for all isolates and within ovine and caprine isolates). Differences in LukMF' production potential between spa types was only tested among types with $\mathrm{n}$ $>10$ using the Kruskal-Wallis test followed by Dunn's test. Fisher's exact tests were performed to study the association between clinical severity and CC, spa type, and lukM-lukF'. Using the same technique, the association between host species and CC and spa type was also investigated. All tests were performed using IBM SPSS Statistics version 24 (IBM Corp., Armonk, NY).

\section{RESULTS}

The results of MLST, spa typing, and presence of lukM-lukF' among S. aureus isolates are reported in Table 1, and an overview of the distribution of CM and SCM over different spa types is shown in Figure 1. Most isolates $(85 \%)$ obtained from goats and sheep belonged to $\mathrm{CC} 133$, and this lineage was present on 15 out of 16 farms (Supplemental Table S1; https://doi.org/10 .3168/jds.2018-16196). Significant differences (Fisher's exact test, $P=0.001$ ) were observed between the CC of caprine and ovine mastitis isolates, with CC398 being exclusively found in goats and CC425 and CC45 found only in sheep (Figure 1). Multiple spa types were present among CC133 isolates, the dominant types being t2678 (40\% of CC133 isolates), t544 (21\%), and t3583 $(21 \%)$. The distribution of the dominant CC133 spa types differed between hosts (Fisher's exact test, $P<$ 0.001). Isolates belonging to $\mathrm{CC} 133 / \mathrm{t} 544$ (ovine: $0 \%$, caprine: $34 \% ; P<0.001$ ) and CC133/t3583 (ovine: $5 \%$, caprine: $30 \% ; P=0.004)$ were associated with caprine mastitis, and those designated CC133/t2678 (ovine: $56 \%$, caprine: $14 \% ; P<0.001)$ were associated with ovine mastitis (Table 1). The spa types t544, t3583, and t2678 were genetically related, as illustrated by the fact that they cluster together in the minimum spanning tree (Figure 1).

Presence of lukM-lukF' was common in CC133 and CC425 but absent in CC45 and CC398 (Table 1). The LukMF' production potential was measured in 71 lukMlukF'-positive isolates, with production levels after $8 \mathrm{~h}$ of culture ranging from 0.4 to $5.0 \mu \mathrm{g} / \mathrm{mL}$. The $\mathrm{CM}$ and SCM isolates produced similar levels of LukM both in ovine (CM: $2.0 \pm 0.9 \mu \mathrm{g} / \mathrm{mL}$, SCM: $2.0 \pm 0.8 \mu \mathrm{g} / \mathrm{mL}$; Mann-Whitney test: $P=0.95)$ and caprine (CM: 3.6 $\pm 0.9 \mu \mathrm{g} / \mathrm{mL}$, SCM: $3.0 \pm 1.0 \mu \mathrm{g} / \mathrm{mL}$; Mann-Whitney test: $P=0.07)$ isolates separately and when comparing all isolates (CM: $2.8 \pm 1.2 \mu \mathrm{g} / \mathrm{mL}, \mathrm{SCM}: 2.5 \pm 1.0 \mu \mathrm{g} /$ $\mathrm{mL}$; Mann-Whitney test: $P=0.28)$. Among the isolates belonging to the 3 dominant spa types (representing $76 \%$ of the total isolate collection), the ovine-associated CC133/t2678 isolates produced LukM at significantly lower levels $(1.9 \pm 0.8 \mu \mathrm{g} / \mathrm{mL})$ than the dominant cap- 
STAPHYLOCOCCUS AUREUS LINEAGES IN SHEEP AND GOATS

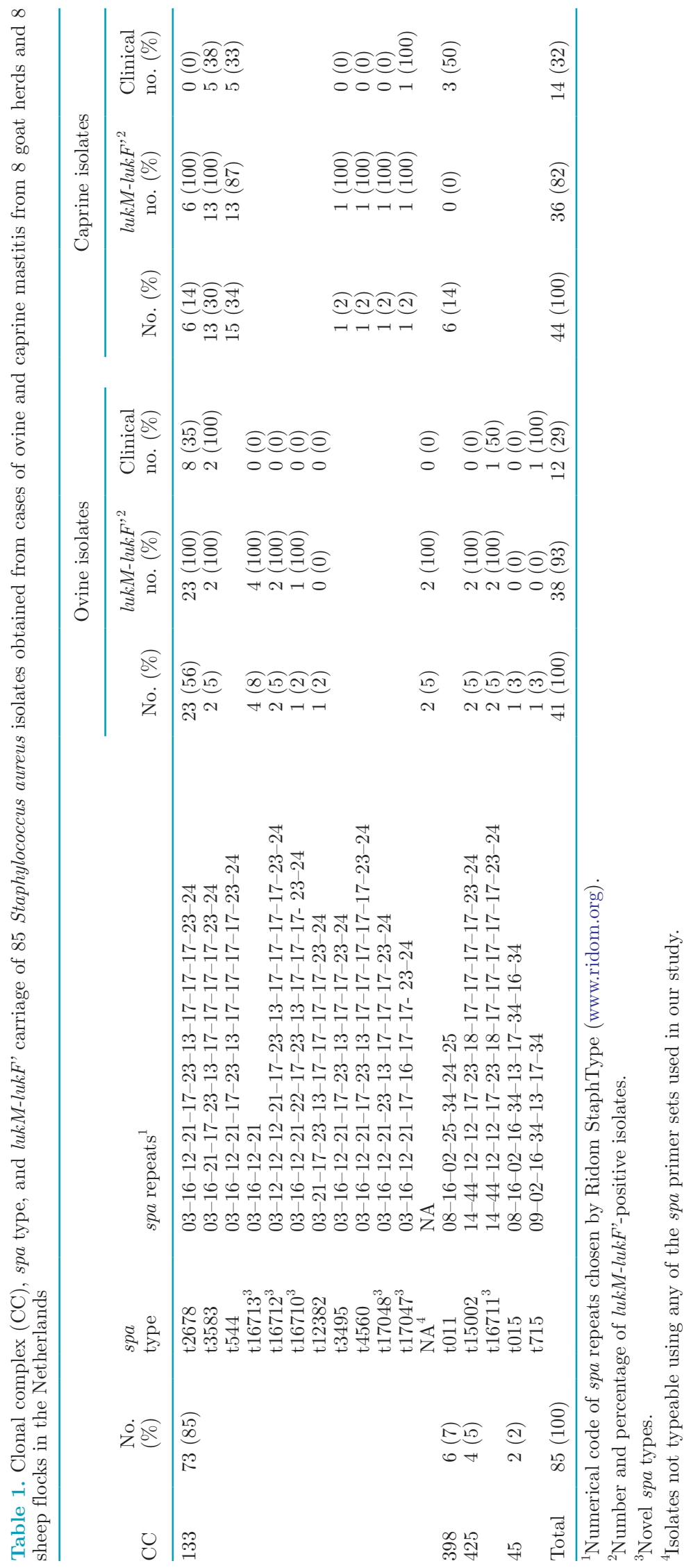




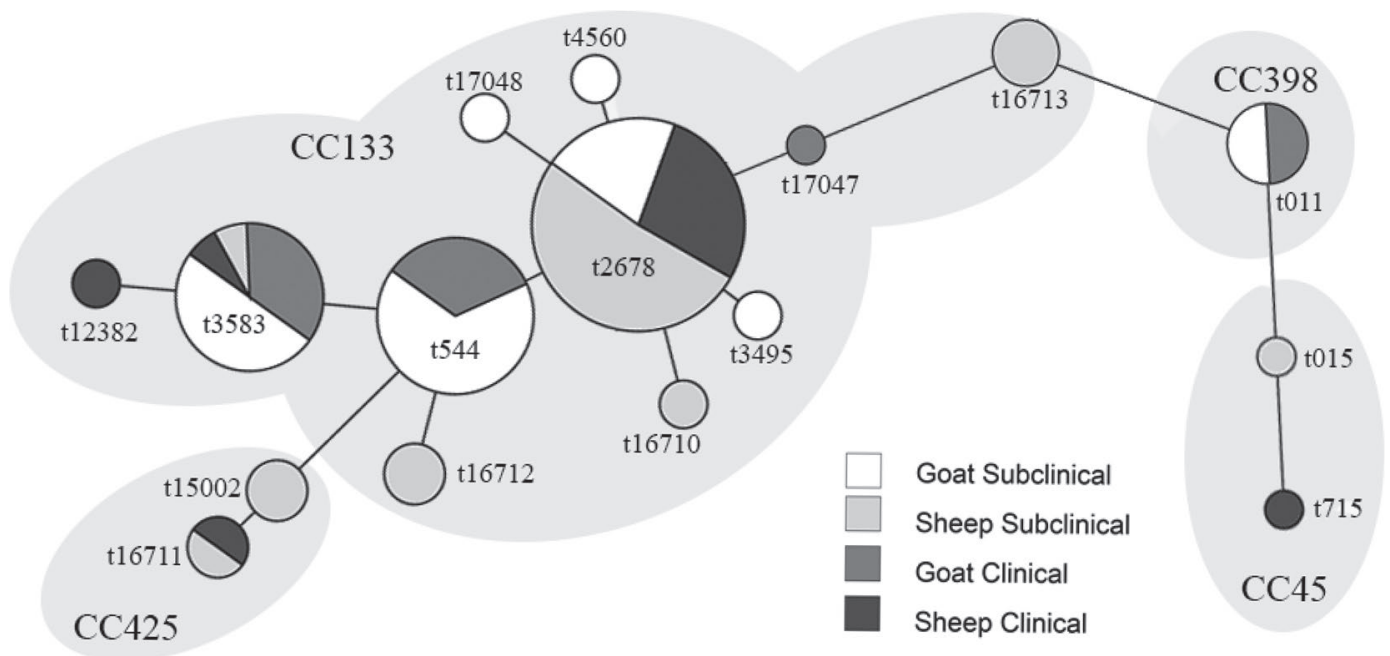

Figure 1. Minimum spanning tree of spa types of ovine $(\mathrm{n}=41)$ and caprine $(\mathrm{n}=44)$ Staphylococcus aureus mastitis isolates cultured from 16 Dutch farms. Each spa type is depicted by a single node, with the size of the node representing the number of isolates associated with this spa type and colors representing host species (goat, sheep) and clinical or subclinical mastitis. Associated clonal complex (CC) is displayed in shading.

rine CC133/t3583 $(3.5 \pm 0.7 \mu \mathrm{g} / \mathrm{mL}$, Dunn's test, $P$ $<0.001)$ and CC133/t544 (3.0 $\pm 1.3 \mu \mathrm{g} / \mathrm{mL}$, Dunn's test, $P=0.007$ ) isolates (Figure 2). A similar but not significant trend was seen in a subset of data using an averaged LukM value per spa type per farm (Supplemental Figure S1; https://doi.org/10.3168/jds.2018 -16196). Fisher's exact tests on all isolates revealed no association between SCM or CM and CC $(P=0.52)$, spa type $(P=0.65)$, or presence of lukM-lukF' $(P=$ $0.25)$. Similar results were seen when the analysis was performed for ovine and caprine isolates separately (results not shown).

\section{DISCUSSION}

In this study, we compared the genotype and LukMF' production potential of $S$. aureus isolates originating from CM and SCM in both goats and sheep. Although most of the caprine and ovine isolates belonged to CC133, the dominant spa type within CC133 found in sheep differed from the ones in goats. Interestingly, isolates from these caprine-associated spa types produced higher levels of LukM in vitro than isolates from the sheep-associated spa type.

The majority of small ruminant mastitis $S$. aureus isolates in this study belonged to CC133, a lineage with a broad host range (Bar-Gal et al., 2015; Monecke et al., 2016), although it has primarily been associated with ruminants, in particular goats and sheep (Smith et al., 2014; Merz et al., 2016; Monecke et al., 2016). Similar observations were made in Denmark, where CC133 was also the dominant lineage found in sheep and goats
(Eriksson et al., 2013). Besides CC133, CC522 and CC130 lineages are considered to be dominant lineages associated with small ruminants (Smith et al., 2014),



Figure 2. The LukM levels in vitro after $8 \mathrm{~h}$ of culture of lukMlukF'-positive Staphylococcus aureus clinical mastitis (triangles) and subclinical mastitis (circles) isolates obtained from sheep (black) and goats (white) belonging to the 3 dominant genotypes, CC133/t3583 $(\mathrm{n}=13), \mathrm{CC} 133 / \mathrm{t} 544(\mathrm{n}=13)$, and CC133/t2678 ( $\mathrm{n}=28)$, tested by ELISA. $\mathrm{CC}=$ clonal complex. Mean LukM production $\pm \mathrm{SD}$ are shown. Production potential of isolates $(n=17)$ belonging to 10 other spa types was measured but is not displayed in this figure. Statistical significance was analyzed by Kruskal-Wallis test followed by Dunn's test. Asterisks indicate a significant difference: ${ }^{* *} P<0.01,{ }^{*} P<0.05$. 
but these types were not found in our study. Although $S$. aureus lineages found among sheep and goats are considered to be highly similar (Merz et al., 2016), systematic differences in spa types between isolates from the 2 host species were observed in this study, with CC133/t2678 being associated with ovine mastitis and CC133/t3583 and CC133/t544 being associated with caprine mastitis. In addition, there were differences in LukMF' production potential, with $\mathrm{CC} 133 / \mathrm{t} 544$ and CC133/t3583 producing on average around 1.5 times more LukM than CC133/t2678. A possible explanation for variation in LukMF' production potential is differences in expression levels of genes involved in the regulation of leukocidin production (Agr quorum-sensing system, SaeRS 2-component systems, Rot; Alonzo and Torres, 2014). Differences in spa repeats between the 3 dominant spa types were small, and CC133/t2678 and CC133/t3583 were not exclusively associated with one host species. Furthermore, previous studies have also described CC133/t544 isolates in sheep (Porrero et al., 2012; Eriksson et al., 2013). Differences in spa type between CC133 S. aureus obtained from sheep and goats have been observed in multiple studies, but the dominant spa type per host species differed per country (Porrero et al., 2012; Eriksson et al., 2013; Azara et al., 2017). It is unclear whether differences in spa type between sheep and goats reflect functional adaptations of the $S$. aureus lineage to the host.

Lineages other than CC133 (CC398, CC425, and CC45) made up only $14 \%$ of mastitis isolates in this study, and all of these lineages have previously been isolated from goats and sheep (Bergonier et al., 2014; Cortimiglia et al., 2015). We found the CC398/t011 lineage only in goats, and CC398 is the predominant lineage of livestock-associated methicillin-resistant $S$. aureus in Europe (Richardson et al., 2018). The CC425 lineage is predominantly associated with $S$. aureus from wildlife origins (Monecke et al., 2016) and was found in only a single sheep flock.

The virulence genes lukM-lukF' were present among most isolates, and we found no relationship between presence of lukM-lukF' or LukMF' production potential and clinical severity of mastitis in sheep or goats. Previously, lukM-lukF'-positive $S$. aureus was associated with CM in cattle (Haveri et al., 2007), and we found that high production of LukMF' was linked with bovine CM (Hoekstra et al., 2018). Presence of lukM-lukF' and production potential of LukMF' are associated with CC (Schlotter et al., 2012; Hoekstra et al., 2018). Most of our isolates (85\%) belong to a single CC, and this could explain why we found no differences in presence and production potential of LukMF' between CM and SCM isolates.
The association between lukM-lukF' and CC133 has previously been reported in bovine, ovine, and caprine isolates (Schlotter et al., 2012; Bar-Gal et al., 2015). However, $2 \mathrm{CC} 133 / \mathrm{t} 544$ isolates, obtained from the same goat herd, lacked lukM-lukF'. Genome analysis revealed that the prophage associated with $l u k M-l u k F^{\prime}$ (phiPV-83; Yamada et al., 2005) was still present in these isolates but lacked the region containing the actual leukocidin genes. All CC425 and the majority of CC133 isolates found in our study carried lukM-lukF', whereas CC425 and CC133 obtained from wildlife ruminant hosts (red deer, roe deer, chamois) rarely harbored lukM-lukF' (Monecke et al., 2016). This could suggest that harboring lukM-lukF' gives S. aureus increased fitness within domesticated ruminants but not within wildlife species.

We found no differences between CM and SCM isolates in sheep or goats. This suggests that the clinical manifestation of mastitis is driven by host factors rather than by the pathogen $S$. aureus. Still, it is possible that differences between $S$. aureus isolates beyond the resolution of the typing methods used in our study determine the outcome of IMI. However, a recent infection study in goats using 2 lineages of $S$. aureus showed that host factors determined the clinical manifestation of mastitis because animals infected with the same $S$. aureus strain had different clinical outcomes (Rainard et al., 2018b).

Mastitis isolates were collected from 8 sheep flocks and 8 goat herds across the Netherlands, but there was an uneven distribution of the number of isolates per farm (Supplemental Table S1; https://doi.org/10.3168/ jds.2018-16196). As a consequence, farm is a potential confounder for observed differences in LukMF' production potential. To compensate for this, a subset using the averaged LukM value per spa type per farm was formed, and similar trends in differences in LukMF' production potential were still present in this subset. The uneven distribution of isolates can also result in over- or underrepresentation of $S$. aureus lineages in our data set, especially in the caprine isolates, because one farm contributed a large number $(43 \%)$ of the caprine isolates (Supplemental Table S1; https://doi.org/10 .3168/jds.2018-16196). However, the spa types found within that goat farm were similar to spa types found on other farms, and the overall variation in spa types between caprine isolates was low. Therefore, we do not expect that this sampling bias substantially affected our main finding that there was no association between genotype and clinical outcome of infection.

Because persistent SCM cases can develop into CM at a later point in time (Lam, 1996; Zadoks et al., 2002), the same strain may be associated with both CM 
and SCM depending on the time of sampling. Additionally, the clinical outcome of an infection is at least in part determined by host factors (Rainard et al., 2018b). This illustrates that the CM or SCM phenotype classification of an isolate based on a single mastitis case is imperfect. However, other studies using the same classification did identify strain variation in pathogenicity of bovine mastitis (Haveri et al., 2007; Hoekstra et al., 2018; Pichette-Jollete et al., 2019). This demonstrates that despite misclassification of strains and the resulting reduction in power, our study approach should in principle be able to identify pathogen-related factors that contribute to severity of an intramammary $S$. aureus infection

Although most mastitis isolates obtained from both sheep and goats belonged to CC133, the CC133/t2678 lineage was associated with ovine mastitis and CC133/ t544 and CC133/t3583 were associated with caprine mastitis. We found no significant differences between $S$. aureus isolated from CM or SCM cases originating from small ruminants, implying that animals with SCM are a reservoir of $S$. aureus responsible for CM. This finding suggests that controlling SCM within a herd is an effective intervention to prevent $\mathrm{CM}$ in small ruminants.

\section{ACKNOWLEDGMENTS}

The authors thank the dairy goat and meat sheep farmers who participated in the study for their contribution.

\section{REFERENCES}

Alonzo, F., III, and V. J. Torres. 2014. The bicomponent pore-forming leucocidins of Staphylococcus aureus. Microbiol. Mol. Biol. Rev. 78:199-230. https://doi.org/10.1128/MMBR.00055-13.

Arsenault, J., P. Dubreuil, R. Higgins, and D. Bélanger. 2008. Risk factors and impacts of clinical and subclinical mastitis in commercial meat-producing sheep flocks in Quebec, Canada. Prev. Vet. Med. 87:373-393. https://doi.org/10.1016/j.prevetmed.2008.05.006.

Azara, E., M. G. Piras, A. Parisi, and S. Tola. 2017. Antimicrobial susceptibility and genotyping of Staphylococcus aureus isolates collected between 1986 and 2015 from ovine mastitis. Vet. Microbiol. 205:53-56. https://doi.org/10.1016/j.vetmic.2017.05.006.

Bar-Gal, G. K., S. E. Blum, L. Hadas, R. Ehricht, S. Monecke, and G. Leitner. 2015. Host-specificity of Staphylococcus aureus causing intramammary infections in dairy animals assessed by genotyping and virulence genes. Vet. Microbiol. 176:143-154. https://doi.org/ 10.1016/j.vetmic.2015.01.007.

Barrón-Bravo, O. G., A. J. Gutiérrez-Chávez, C. A. Ángel-Sahagún, H. H. Montaldo, L. Shepard, and M. Valencia-Posadas. 2013. Losses in milk yield, fat and protein contents according to different levels of somatic cell count in dairy goats. Small Rumin. Res. 113:421-431. https://doi.org/10.1016/j.smallrumres.2013.04.003.

Bergonier, D., R. de Crémoux, R. Rupp, G. Lagriffoul, and X. Berthelot. 2003. Mastitis of dairy small ruminants. Vet. Res. 34:689-716. https://doi.org/10.1051/vetres:2003030.

Bergonier, D., D. Sobral, A. T. Feßler, E. Jacquet, F. B. Gilbert, S. Schwarz, M. Treilles, P. Bouloc, C. Pourcel, and G. Vergnaud. 2014. Staphylococcus aureus from 152 cases of bovine, ovine and caprine mastitis investigated by multiple-locus variable number of tandem repeat analysis (MLVA). Vet. Res. 45:97. https://doi.org/ 10.1186/s13567-014-0097-4.

Conington, J., G. Cao, A. Stott, and L. Bünger. 2008. Breeding for resistance to mastitis in United Kingdom sheep, a review and economic appraisal. Vet. Rec. 162:369-376.

Cortimiglia, C., V. Bianchini, A. Franco, A. Caprioli, A. Battisti, L. Colombo, K. Stradiott, F. Vezzoli, and M. Luini. 2015. Short communication: Prevalence of Staphylococcus aureus and methicillinresistant $S$. aureus in bulk tank milk from dairy goat farms in Northern Italy. J. Dairy Sci. 98:2307-2311. https://doi.org/10 $.3168 / \mathrm{jds} .2014-8923$.

de los Campos, G., D. Gianola, P. Boettcher, and P. Moroni. 2006 A structural equation model for describing relationships between somatic cell score and milk yield in dairy goats. J. Anim. Sci. 84:2934-2941. https://doi.org/10.2527/jas.2006-016.

Eriksson, J., C. Espinosa-Gongora, I. Stamphøj, A. R. Larsen, and L. Guardabassi. 2013. Carriage frequency, diversity and methicillin resistance of Staphylococcus aureus in Danish small ruminants. Vet. Microbiol. 163:110-115. https://doi.org/10.1016/j.vetmic 2012.12.006.

Fournier, C., P. Kuhnert, J. Frey, R. Miserez, M. Kirchhofer, T. Kaufmann, A. Steiner, and H. U. Graber. 2008. Bovine Staphylococcus aureus: Association of virulence genes, genotypes and clinical outcome. Res. Vet. Sci. 85:439-448. https://doi.org/10.1016/j .rvsc.2008.01.010.

Fthenakis, G. C. 1994. Prevalence and aetiology of subclinical mastitis in ewes of Southern Greece. Small Rumin. Res. 13:293-300. https: //doi.org/10.1016/0921-4488(94)90078-7.

Gonzalo, C., A. Ariznabarreta, J. A. Carriedo, and F. San Primitivo. 2002. Mammary pathogens and their relationship to somatic cell count and milk yield losses in dairy ewes. J. Dairy Sci. 85:14601467. https://doi.org/10.3168/jds.S0022-0302(02)74214-8.

Gougoulis, D. A., and I. Kyriazakis. 2010. Diagnostic significance of behaviour changes of sheep: A selected review. Small Rumin. Res. 92:52-56. https://doi.org/10.1016/j.smallrumres.2010.04.018.

Hallin, M., A. W. Friedrich, and M. J. Struelens. 2009. Spa typing for epidemiological surveillance of Staphylococcus aureus. Methods Mol. Biol. 551:189-202. https://doi.org/10.1007/978-1-60327-999 $-4 \_15$.

Haveri, M., A. Roslöf, L. Rantala, and S. Pyörälä. 2007. Virulence genes of bovine Staphylococcus aureus from persistent and nonpersistent intramammary infections with different clinical characteristics. J. Appl. Microbiol. 103:993-1000. https://doi.org/10.1111/j .1365-2672.2007.03356.x.

Hoekstra, J., V. P. M. G. Rutten, L. S. Sommeling, T. van Werven, M. P. Spaninks, B. Duim, L. Benedictus, and G. Koop. 2018. High production of LukMF' in Staphylococcus aureus field strains is associated with clinical bovine mastitis. Toxins (Basel) 10:200. https: //doi.org/10.3390/toxins10050200.

Hogan, J. S. 1999. Laboratory Handbook on Bovine Mastitis. National Mastitis Council, Madison, WI.

Jang, K. S., and Y. H. Kim. 2018. Rapid and robust MALDI-TOF MS techniques for microbial identification: A brief overview of their diverse applications. J. Microbiol. 56:209-216. https://doi.org/10 $.1007 / \mathrm{s} 12275-018-7457-0$.

Koop, G. 2012. Udder health in dairy goats. Dissertation. Utrecht University, the Netherlands.

Koop, G., T. van Werven, H. J. Schuiling, and M. Nielen. 2010. The effect of subclinical mastitis on milk yield in dairy goats. J. Dairy Sci. 93:5809-5817. https://doi.org/10.3168/jds.2010-3544.

Lam, T. J. G. M. 1996. Dynamics of bovine mastitis: A field study in low somatic cell count herds. PhD Dissertation. Utrecht University, the Netherlands.

Martí De Olives, A., J. R. Díaz, M. P. Molina, and C. Peris. 2013 Quantification of milk yield and composition changes as affected by subclinical mastitis during the current lactation in sheep. J. Dairy Sci. 96:7698-7708. https://doi.org/10.3168/jds.2013-6998.

Mekonnen, S. A., T. J. G. M. Lam, J. Hoekstra, T. S. Tessema, E. M. Broens, A. E. Riesebos, M. P. Spaninks, and G. Koop. 2018. Characterization of Staphylococcus aureus isolated from milk samples of 
dairy cows in small holder farms of North-Western Ethiopia. BMC Vet. Res. 14:246.

Merz, A., R. Stephan, and S. Johler. 2016. Staphylococcus aureus isolates from goat and sheep milk seem to be closely related and differ from isolates detected from bovine milk. Front. Microbiol. 7:319. https://doi.org/10.3389/fmicb.2016.00319.

Monecke, S., D. Gavier-Widén, H. Hotzel, M. Peters, S. Guenther, A. Lazaris, I. Loncaric, E. Müller, A. Reissig, A. Ruppelt-Lorz, A. C. Shore, B. Walter, D. C. Coleman, and R. Ehricht. 2016. Diversity of Staphylococcus aureus isolates in European wildlife. PLoS One 11:e0168433. https://doi.org/10.1371/journal.pone.0168433.

Moroni, P., G. Pisoni, G. Ruffo, and P. J. Boettcher. 2005. Risk factors for intramammary infections and relationship with somatic-cell counts in Italian dairy goats. Prev. Vet. Med. 69:163-173. https:/ /doi.org/10.1016/j.prevetmed.2004.10.013.

Pichette-Jolette, S., G. Millette, E. Demontier, D. Bran-Barrera, M. Cyrenne, C. Ster, D. Haine, G. Keefe, F. Malouin, and J. P. Roy. 2019. Partial prediction of the duration and the clinical status of Staphylococcus aureus bovine intramammary infections based on the phenotypic and genotypic analysis of isolates. Vet. Microbiol. 228:188-195. https://doi.org/10.1016/j.vetmic.

Porrero, M., H. Hasman, A. I. Vela, J. F. Fernández-Garayzábal, L. Domínguez, and F. M. Aarestrup. 2012. Clonal diversity of Staphylococcus aureus originating from the small ruminants goats and sheep. Vet. Microbiol. 156:157-161. https://doi.org/10.1016/ j.vetmic.2011.10.015.

Rainard, P., G. Foucras, J. R. Fitzgerald, J. L. Watts, G. Koop, and J. R. Middleton. 2018a. Knowledge gaps and research priorities in Staphylococcus aureus mastitis control. Transbound. Emerg. Dis. 65:149-165. https://doi.org/10.1111/tbed.12698.

Rainard, P., C. Gitton, T. Chaumeil, T. Fassier, C. Huau, M. Riou, G. Tosser-Klopp, Z. Krupova, A. Chaize, F. B. Gilbert, R. Rupp, and P. Martin. 2018b. Host factors determine the evolution of infection with Staphylococcus aureus to gangrenous mastitis in goats. Vet. Res. 49:72. https://doi.org/10.1186/s13567-018-0564-4.

Richardson, E. J., R. Bacigalupe, E. M. Harrison, L. A. Weinert, S. Lycett, M. Vrieling, K. Robb, P. A. Hoskisson, M. T. G. Holden, E. J. Feil, G. K. Paterson, S. Y. C. Tong, A. Shittu, W. van
Wamel, D. M. Aanensen, J. Parkhill, S. J. Peacock, J. Corander, M. Holmes, and J. R. Fitzgerald. 2018. Gene exchange drives the ecological success of a multi-host bacterial pathogen. Nat. Ecol. Evol. 2:1468-1478. https://doi.org/10.1038/s41559-018-0617-0.

Schlotter, K., R. Ehricht, H. Hotzel, S. Monecke, M. Pfeffer, and K. Donat. 2012. Leukocidin genes LukF-P83 and LukM are associated with Taphylococcus aureus clonal complexes 151, 479 and 133 isolated from bovine udder infections in Thuringia, Germany. Vet. Res. 43:42. https://doi.org/10.1186/1297-9716-43-42.

Smith, E. M., P. F. Needs, G. Manley, and L. E. Green. 2014. Global distribution and diversity of ovine-associated Staphylococcus aureus. Infect. Genet. Evol. 22:208-215. https://doi.org/10.1016/j .meegid.2013.09.008.

Smith, M. C., and D. M. Sherman. 2009. Goat Medicine. Wiley-Blackwell, Oxford, UK.

Vasileiou, N. G. C., P. J. Cripps, K. S. Ioannidi, D. C. Chatzopoulos, D. A. Gougoulis, S. Sarrou, D. C. Orfanou, A. P. Politis, T. C. Gonzalez-Valerio, S. Argyros, V. S. Mavrogianni, E. Petinaki, and G. C. Fthenakis. 2018. Extensive countrywide field investigation of subclinical mastitis in sheep in Greece. J. Dairy Sci. 101:72977310. https://doi.org/10.3168/jds.2017-14075.

Vrieling, M., E. M. Boerhout, G. F. van Wigcheren, K. J. Koymans, T. G. Mols-Vorstermans, C. J. de Haas, P. C. Aerts, I. J. Daemen, K. P. van Kessel, A. P. Koets, V. P. Rutten, P. J. Nuijten, J. A. van Strijp, and L. Benedictus. 2016. LukMF' is the major secreted leukocidin of bovine Staphylococcus aureus and is produced in vivo during bovine mastitis. Sci. Rep. 6:37759. https://doi.org/10 .1038/srep37759.

Yamada, T., N. Tochimaru, S. Nakasuji, E. Hata, H. Kobayashi, M. Eguchi, J. Kaneko, Y. Kamio, T. Kaidoh, and S. Takeuchi. 2005. Leukotoxin family genes in Staphylococcus aureus isolated from domestic animals and prevalence of LukM-LukF-PV genes by bacteriophages in bovine isolates. Vet. Microbiol. 110:97-103. https:/ /doi.org/10.1016/j.vetmic.2005.07.006.

Zadoks, R. N., H. G. Allore, T. J. Hagenaars, H. W. Barkema, and Y. H. Schukken. 2002. A mathematical model of Staphylococcus aureus control in dairy herds. Epidemiol. Infect. 129:397-416. 